\title{
GEOPOLÍTICA DO LÍTIO NO SÉCULO XXI
}

\author{
Bernardo Salgado Rodrigues ${ }^{1}$ \\ Raphael Padula ${ }^{2}$
}

\section{Introdução}

Por conta da presença abundante de recursos naturais comuns e raros, a América do Sul é considerada altamente estratégica para a nova etapa de acumulação capitalista e para a reprodução de seu modo de produção, inserindo-se numa nova pressão competitiva mundial que tende a se acentuar ainda mais com o aumento da demanda mundial pelo recurso. Em termos geopolíticos, tudo indica que a região foi incorporada na pressão competitiva mundial em que algumas regiões "devem se transformar em 'zonas de fratura' internacional, e aí podem surgir conflitos e rebeliões que envolvam as grandes potências e as empresas que competem pelo controle da região" (Fiori 20I4, I6I).

O presente artigo busca avaliar a geopolítica do lítio no século XXI a partir das disputas geopolíticas nacionais, regionais e globais, que colocam a América do Sul no centro do debate e criam possíveis novas tensões na região andina do subcontinente. Nossa hipótese é de que o lítio se configura como um dos recursos naturais mais estratégicos, cujas reservas mundiais, quantitativamente e qualitativamente, se concentram na região sul-americana, tendo como base metodológica uma revisão bibliográfica e qualitativa de dados

\footnotetext{
I Doutorando em Economia Política Internacional pela Universidade Federal do Rio de Janeiro (UFRJ-PEPI). Mestre em Economia Política Internacional da Universidade Federal do Rio de Janeiro (UFRJ-PEPI). Atualmente é integrante do Laboratório de Estudos de Hegemonia e Contrahegemonia (LEHC-UFRJ) e membro do Grupo de Trabalho de Integração e Unidade Latino-Americana e Caribenha do CLACSO (Conselho Latino-americano de Ciências Sociais). E-mail: bernardo.rodrigues@pepi.ie.ufrj.br

2 Coordenador da Pós-Graduação em Economia Política Internacional (PEPI) do Instituto de Economia (IE/UFRJ), Professor Adjunto da Universidade Federal do Rio de Janeiro (UFRJ) da área de Economia Política Internacional, atua na graduação de Relações Internacionais, lecionando disciplinas de Geopolítica, Teoria Política Internacional, Economia Internacional e Integração Regional. E-mail: padula.raphael@gmail.com
} 
estatísticos sobre o tema presentes em estudos e documentos de governo, sendo de suma importância a realização de uma análise que abranja o estudo de seu comportamento referente às reservas, à produção, aos preços, à oferta, à demanda e uma análise geográfica.

\section{Características do lítio}

O lítio é um metal alcalino, o átomo de menor tamanho e o mais leve entre todos os metais da tabela periódica, sob condições normais de temperatura e pressão. Por causa de sua baixa massa atômica, ele tem uma alta carga e uma potência específica.Ele não é encontrado em seu estado nativo; ou seja, não existe livre na natureza, sendo localizado na maioria das vezes na condição de composto químico iônico. Além disso, devido ao seu elevado calor específico é usado em aplicações de transferência de calor e, por causa do seu elevado potencial eletroquímico e alta densidade energética, é usado como um ânodo adequado para as baterias elétricas. Por exemplo, uma bateria de íons de lítio típica pode gerar aproximadamente 3 volts por célula, comparado com 2,I volts para a bateria de ácido de chumbo ou I, 5 volts de células de zinco-carbono.

Quanto às suas aplicações, é utilizado na obtenção de ligas metálicas condutoras de calor (alumínio), no feitio de cerâmicas e lentes (telescópios), em graxas lubrificantes, em aplicações militares (aditivos energéticos nos propelentes dos foguetes e em bombas de hidrogênio), na medicina (medicamentos para depressão e transtorno bipolar), na indústria elétrica e eletrônica (produção de pilhas e baterias elétricas, como celulares, notebooks e carros híbridos/elétricos), dentre outros.

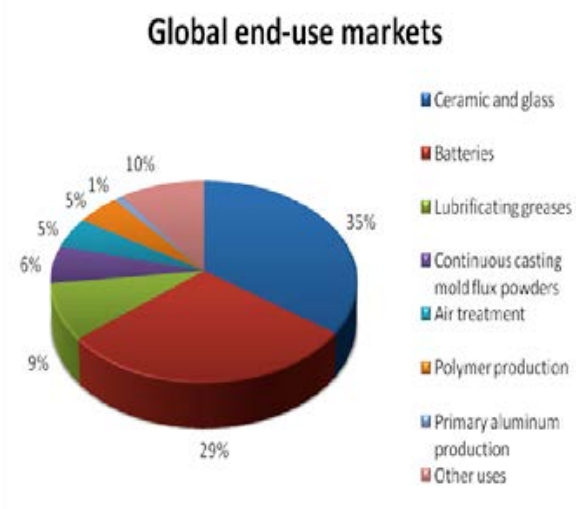

Fonte v3 Geological Surrey, Minenl Commodty Sunmares, Fetnuay 2014 (e'ácryçloprobra)
World: Estimated lithium consumption by end-use, 2011

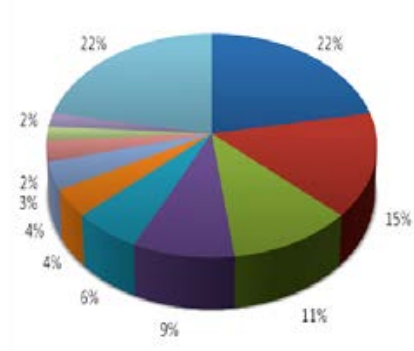

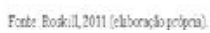

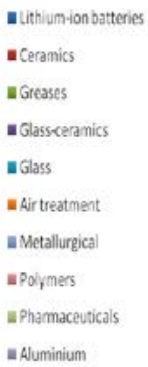

wother 
A demanda por lítio manteve-se praticamente inalterada desde seu descobrimento em I8I7, pelo químico sueco Johan August Arfwedson. Ao longo dos anos, suas propriedades foram sendo ajustadas para as necessidades de desenvolvimento tecnológico em diversos setores, mas suas qualidades como transmissor de energia se ressaltaram, principalmente nos anos i970, a partir "de un paradigma tecnológico asociado a la informática y la electrónica, del que deriva una serie de aparatos y herramientas que, cada vez más, usan baterías de litio" (Palacio 20ı2, 6), como é o caso das baterias de aparelhos eletrônicos e carros elétricos híbridos. Logo, a partir da década de I990, esse quadro se modifica com a proliferação, principalmente, dos telefones celulares e dos computadores portáteis.

A partir do início do século XXI, com o surgimento da alta demanda por baterias iônicas de lítio, as novas companhias têm expandido a extração do lítio para atender as indústrias deste setor. Por causa disso, desde 2007, o mercado de lítio tem como seu maior consumidor as indústrias de baterias iônicas de lítio, com projeções futuras ainda maiores.

\section{Lithium Market Growth Rate Forecast}

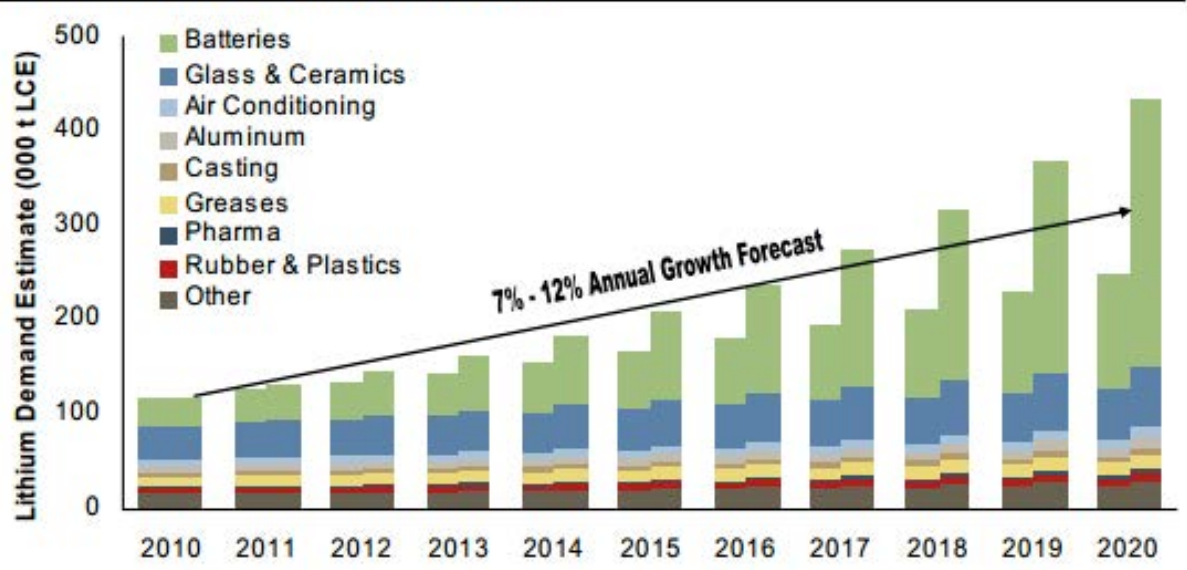

Fonte: Cormarck Securities Inc. 2011; Baylis 2012.

Logo, percebe-se que a importância estratégica do lítio - consequência de uma inovação tecnológica e sua aplicabilidade na indústria de baterias recarregáveis de quase todos os dispositivos eletrônicos portáteis consumidos no mundo - é latente. Entretanto, talvez sua aplicação mais importante, sob o ponto de vista tecnológico e ambiental, seja na produção de uma nova tecnologia de baterias recarregáveis para veículos elétricos e híbridos: o EV (Electric Vehicle), este movido apenas a eletricidade, sendo carregado em uma tomada elétrica, e o veículo hibrido elétrico plug-in, o PHEV (Plug-in Hybrid Electric 
Vehicle).

A vantagem da nova tecnologia de baterias de íon-lítio é sua alta densidade de energia, o que lhe permite maior capacidade de armazenamento de energia por unidade de peso, reduzindo consideravelmente o peso total destas baterias em relação àquelas produzidas a partir de NiCd (nickel-cadmium battery) ou de NiMH (Nickel-metal hydride battery). Em I992, quando se introduziram no mercado as baterias de lítio, estas tinham densidade de energia apenas I0\% maior que as baterias de NiMH. Em 2005, a densidade de energia média das baterias de lítio era $80 \%$ maior que a das baterias de NiMH. Em 2009, como parte de seu programa de energia, o governo estadunidense concedeu 24.000 mil horas à IBM em dois laboratórios nacionais, Argonne e Oak Ridge, para pesquisas destinadas a aumentar a funcionalidade de baterias para carros elétricos (Palacio 2012, 6).

O aumento da densidade de energia das baterias de lítio tem permitido a diminuição constante do peso total destas e, consequentemente, a diminuição do peso dos dispositivos portáteis que as usam. No caso dos veículos elétricos híbridos, a alta densidade de energia das baterias de lítio é fundamental (Viana, Barros e Calixtre 20II, 2I9).

Mesmo com os desenvolvimentos tecnológicos no ramo científico do lítio, alguns estudiosos ainda consideram as baterias grandes e pesadas, além da sua reatividade ser outra fonte de problemas. Ainda assim, cientistas vêm abrindo novos caminhos, trabalhando numa bateria "lítio-ar"3. Nelas, em vez de ser selado num invólucro, o lítio permanece em contato com o ar, e usa o oxigênio ambiente como catodo, a exemplo do que fazem as baterias de zinco dos aparelhos de audição, tornando a bateria bem mais leve. Há ainda cientistas que vem usando a nanotecnologia para tornar mais densa a superfície do catodo, o que poderá multiplicar o número de reações e aumentar, ao menos em teoria, a potência da bateria.

O uso do lítio nestes ramos industriais é muito recente. No entanto, seu crescente consumo em diversos setores estratégicos tem aumentado o seu consumo mundial ao longo dos últimos 30 anos. Dessa forma, seu mapeamento regional/mundial e suas disputas geopolíticas são fundamentais para compreender sua crescente importância no cenário internacional ao

3 "Uma nova tecnologia, a bateria de lítio-ar, pode ser capaz de aumentar a densidade de energia de baterias de lítio, efetivamente rivalizando com a densidade de energia do petróleo. Embora o desenvolvimento da tecnologia de bateria de lítio-ar ainda está em sua infância, uma coalizão de laboratórios norte-americanos e parceiros comerciais liderados pela International Business Machines Corp. antecipou ter um protótipo de laboratório preparado até 2013 , um protótipo ampliado capaz de alimentar um carro pronto até 2015 , e baterias comerciais em produção dentro de uma década" (United States 20I2, tradução nossa). 
longo dos anos, e principalmente na atualidade, com sua utilização para fins científicos e tecnológicos.

Neste contexto, ressalta-se como a presença do lítio na América do Sul vem despertando disputas geopolíticas nacionais, regionais e globais, colocando a região no centro do debate e criando possíveis novas tensões na região andina do subcontinente.

\section{Geopolítica do lítio}

O ambiente externo com que cada Estado se depara ao traçar sua própria estratégia - ambiente que envolve a presença de outros Estados, também lutando pela sobrevivência e por vantagens -, alinhado com períodos de convulsão global e de constantes inovações tecnológicas, conduz a um renascimento nas ideias sobre geografia (Kaplan 2013, 62). Tal é o caso do lítio, cujo ciclo tecnológico inicia-se entre 2000 e 2005 e possui uma previsão de uso intensivo até o período 2035-2045, segundo as estimativas de Bruckmann (20II, 2I7-2I9).

Para uma análise de estudo de caso da geopolítica do lítio na América do Sul, é de suma importância a realização de uma análise que abranja o estudo de seu comportamento referente às reservas, à produção, aos preços, à oferta, à demanda e uma análise geográfica.

As reservas de lítio podem ser encontradas a partir de dois tipos distintos de concentrações de sais de lítio: em minas de rocha dura, principalmente na Austrália, que produzem concentrados minerais de lítio para fins técnicos e conversão em produtos químicos de lítio, quase exclusivamente na China; e em salmouras continentais, por exemplo, os salares na Argentina, Chile, China e Afeganistão, mais utilizados para a produção de carbonato de lítio, hidróxido e cloreto. Geralmente, essas regiões são consideradas como de menor custo de exploração e, portanto, mais comercialmente viável em comparação com minerais de lítio - embora ambos estejam localizados em locais remotos e apresentem desafios técnicos e logísticos muito diferentes.

As principais reservas encontram-se em regiões de salares, terras que há dezenas de milhares de anos eram cobertas por oceanos e, com a formação geológica dos continentes, acabaram secando e formando grandes desertos de sal. O lítio se encontra dissolvido abaixo da grossa crosta, em uma camada de solução impregnada de sal. O fato de ser um mineral que se concentra em região de salares faz com que países como Bolívia, com o Salar de Uyuni, Chile, com o Salar de Atacama, e Argentina, com o Salar del Hombre Muerto, estejam situados entre os maiores detentores mundiais de reservas deste recurso, 
formando o chamado "triângulo do lítio", apresentando aproximadamente 92\% das reservas mundiais em 2009 (Bruckmann 20II, 219).

A contabilidade das reservas mundiais de lítio varia de acordo com as agências e empresas que a realizam, como demonstram vários informes e a tabela abaixo. No entanto, a sua grande concentração geográfica na região andina da América do Sul é um dado incontestável.

\section{Estimativa dos recursos mundiais de lítio (em milhões de toneladas)}

\begin{tabular}{|c|c|c|c|}
\hline Pais & Mt LI met. & Fuentes & \\
\hline Bolivia & 8,90 & COMIBOI & (1) \\
\hline Chile & 8,04 & Roskill (7013), SQM, CORIO & (1) \\
\hline Argentina & 7,09 & Compañias mineras _ & $(2)$ \\
\hline China & 5,15 & Roskill (2013) & (1) \\
\hline EEUU & 1,67 & Companíías mineras & (2)(3) \\
\hline Australia & 1,55 & Compañias mineras & (2) \\
\hline Congo & 1,15 & Roskill (2013) & (1) \\
\hline Serbia & 1,05 & Roskill (2013) & (4) \\
\hline Rusia & 1,00 & Evans (2012), USGS (2013) & (1) \\
\hline Canadá & 0,74 & Compañias mineras, Roskill (2013) & (2) \\
\hline Brasil & 0,10 & Roskill (2013) & (1) \\
\hline Limbawe & 0,06 & USGS (2012) & (1) \\
\hline Austria & 0,05 & Global Strategic Metals & (2) \\
\hline Portugal & 0,01 & Roskill $(\overline{2013})$ & (1) \\
\hline Otros & 0,20 & Estimación propia en base a Roskill (2013) & (1) \\
\hline TOTAL & 36,74 & & \\
\hline
\end{tabular}

(1) Valor referencial, se desconoce metodología y parámetros utilizados.

(2) Se consideraron recursos medidos e indicados publicados por las empresas mineras.

(3) Según USGS (2013) los recursos de EEUU ascienden a 5,5 Mt. Sin embargo, se desconocen los yacimientos incluidos y los parámetros utilizados de este cálculo.

(4) Recurso inferido publicado en Roskill (2013).

\section{Fonte: Cochilco 2013.}

Ainda que sob metodologias e parâmetros contábeis utilizados de maneira distinta, uma vez que há distinções dos modelos de acordo com as empresas ou agências que realizam as prospecções, o fato é que Bolívia, Chile e Argentina possuem grandes quantidades percentuais das reservas mundiais de lítio no ano de 20I3. A imagem abaixo ratifica tal argumento, no qual a América do Sul teria aproximadamente 7I\% das reservas de lítio, sendo a Bolívia com 34\%, o Chile com 31\% e a Argentina com 6\%. 


\section{Reservas de lítio por país}

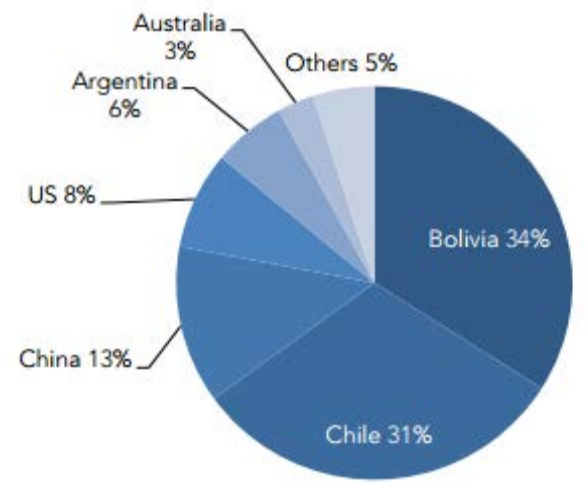

Fonte: Fox-Davies 2013.

Desde que se intensificou a utilização do lítio em escala comercial, a sua produção mundial aumentou exponencialmente, sendo ainda mais intensificada a partir dos anos 2000, como demonstra o gráfico abaixo.

\section{Produção Mundial de Lítio}

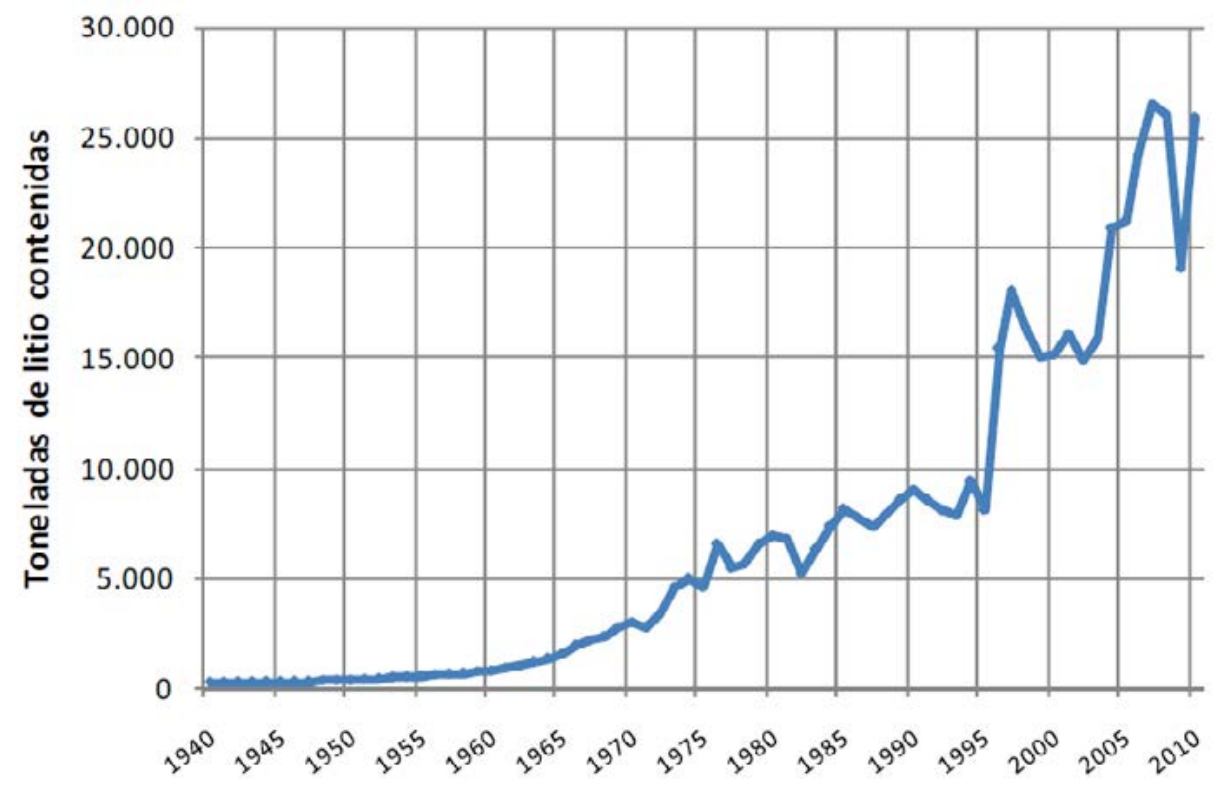

Fonte: Lagos 2011.

Entretanto, os preços internacionais do lítio - que são publicados 
pelos principais produtores e negociados diretamente entre compradores e usuários finais com grupos da indústria e governos, não havendo um mercado de terminais e praticamente nenhum mercado à vista de terceiros - não vêm acompanhando este alto ritmo de crescimento da produção mundial. $\mathrm{Na}$ medida em que a produção mundial aumenta, os preços do carbonato de lítio registram oscilações e um desacoplamento com sua produção.

\section{Evolução dos preços de carbonato de lítio (1953-2008)}

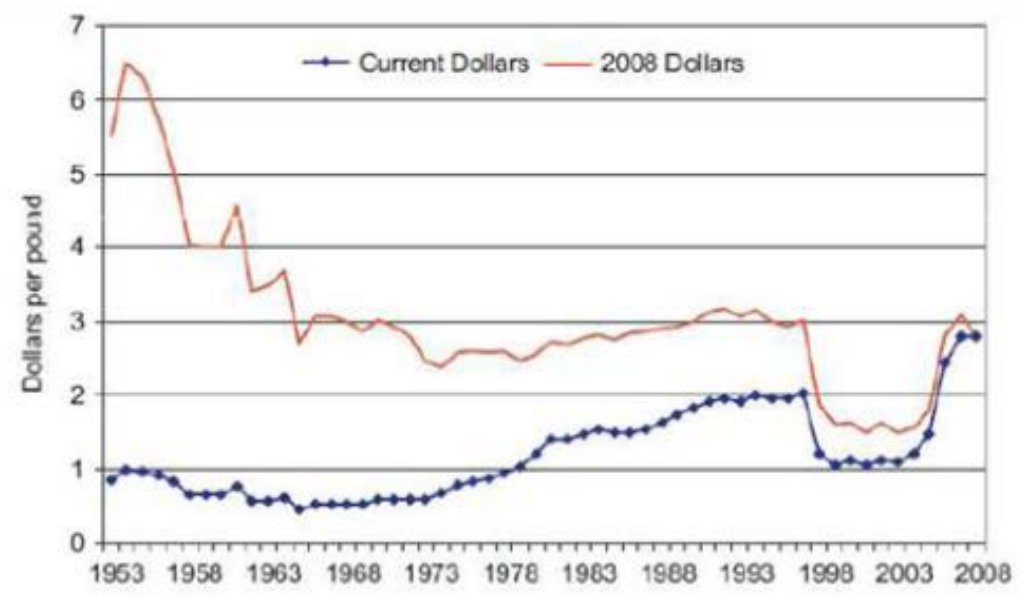

Fonte: Libertad y Desarrollo 2012.

Convém observar o comportamento dos preços entre I953 e 2009. Entre esses anos, o preço do lítio aumentou somente em menos de $20 \%$ que o IPC dos Estados Unidos (Libertad y Desarrollo 20I2). Ou seja, os preços internacionais apresentam um fraco crescimento em dólares correntes, e até mesmo queda quando considerado o ano-base de 2008.

No início de I990, os preços do carbonato de lítio eram em média $\$ 4.000 / t$, caindo para $\$ \mathrm{I} .600 / \mathrm{t}$ por vários anos, principalmente quando a chilena SQM - Sociedad Química e Minera de Chile S.A. - entrou no mercado em meados dos anos I990. A partir dos anos 2000, com o aumento da demanda, o preço do lítio vinha aumentado gradualmente até atingir um pico de 6.500 dólares/t em 2008. Em 2009, os preços caíram impulsionados pela crise global, e, desde então, manteve-se relativamente estável em 5.000 \$/t. As previsões são de que, nos próximos anos, se tenham preços estáveis, de aproximadamente $\$ 6.000 / \mathrm{t}$, com previsões de aumento dependendo da nova estrutura de mercado (Cormark Securities Inc. 20II). 
Ainda do gráfico acima, pode-se concluir cinco fatos geopolíticos relativos aos preços internacionais do lítio: I - mudança de uma produção duopólica do mercado do lítio até meados dos anos I990, quando se tem a entrada da SQM - o que explica em parte a queda acentuada dos preços na segunda parte da década de I990 - e da australiana Talison em 2007; 2 - ainda nos anos I990, o desenvolvimento em larga escala dos recursos em salares com menores custos, como no Chile e na Argentina, por SQM, a alemã Rockwood e a norte-americana FMC, modificaram o fornecimento mundial de lítio com a diminuição dos preços, inclusive encerrando operações em outras partes do mundo que tinham custos mais elevados, como nos EUA, na Rússia e na China e que, em certa medida, também explicam a curva descendente dos preços em meados dos anos I990; 3 - com a crise de 2008, os preços internacionais desaceleram a tendência de alta visualizada no começo dos anos $2000 \mathrm{com}$ o aumento da demanda, tendo uma leve redução, mas que, posteriormente, é retomada sua ascendência; 4 - a tendência mundial a partir dos anos 20Io, a médio-longo prazo, será de um forte aumento da demanda influenciado pela Ásia, cujo principal fornecimento decorrerá da Austrália - devido a sua proximidade geográfica -, Argentina, Chile e de novas fontes que sejam economicamente viáveis. Em outros termos, o custo marginal da oferta será um fator importante para a base dos preços internacionais do lítio nos próximos anos; e 5 - uma vez que 70\% das reservas mundiais do minério se encontram na América do Sul, com custos menores e com pureza mais elevada, esse conjunto de três países terá importante participação no estabelecimento dos preços.

Assim, no que se refere à oferta mundial, quatro países concentram $92 \%$ da oferta (Chile 38\%, Austrália 31\%, Argentina 13\% e China 10\%) e quatro empresas concentram 80\% (Talison 35\%, SQM 26\%, Rockwood I2\% e FMC 7\%), como demonstrado na imagem abaixo.
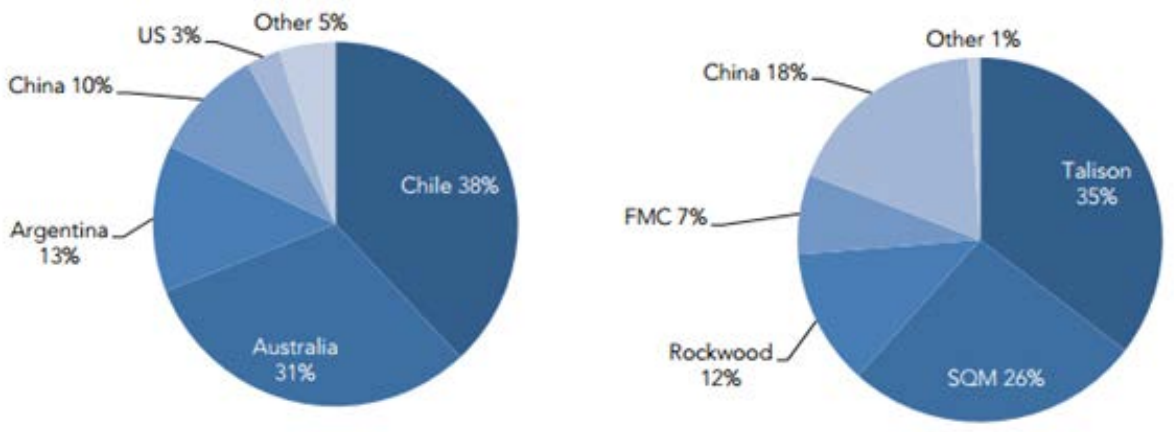

Fonte: Fox-Davies 2013. 
A australiana Talison Lithium é a maior produtora de lítio no mundo, fornecendo aproximadamente $35 \%$ do mercado mundial de lítio e a empresa dominante de vidro e indústria cerâmica com alta pureza, além de ser o principal fornecedor de carbonato de lítio para o mercado chinês ${ }^{4}$. Na América do Sul, possui um projeto em desenvolvimento em Salares 7, localizado na Região III, Chile (Cormark Securities Inc. 20II).

Em 20I4, a chinesa Chengdu Tianqi Industry Group Co. (Tianqi), uma sociedade anônima privada líder na produção de produtos químicos de lítio, acertou a compra da Talison com o apoio do governo chinês, possuindo 51\% - os demais 49\% pertencentes a Rockwood5. Desde I997, com a ajuda de bancos, departamentos governamentais e outros parceiros, o agregado econômico da Tianqi tem mantido um crescimento constante de $40 \%$ ao ano ${ }^{6}$. Com ambiciosos planos para atender a crescente demanda, a empresa está se tornando rapidamente uma empresa líder internacional em novas energias e novos materiais, dentre os quais o lítio aparece como uma de suas prioridades.

Nas regiões de salares, três empresas se destacam: a chilena SQM (Sociedad Química y Minera de Chile SA), a alemã Rockwood Holdings (que inclui Chemetall, da Alemanha, desde 2004, a Cyprus Foote, dos EUA e a SCL, do Chile) e a norteamericana FMC Coporation. A maior participação de mercado em salares possui a SQM, com $26 \%$, a partir de sua produção no Salar de Atacama (Chile). A Rockwood vem em seguida, com uma participação de I2\%, a partir de plantas no Salar de Atacama com a Sociedad Chilena del Litio Ltda - SCL e Silver Peak, em Nevada, nos Estados Unidos. Em terceiro, a FMC, com operações no Salar del Hombre Muerto (Argentina), representando $7 \%$ do mercado. Dessas empresas, FMC e Rockwood usam a maior parcela de sua produção de lítio internamente para a produção de produtos químicos de valor agregado, deixando à SQM o suprimento da maioria de carbonato de lítio consumida diretamente pelos usuários finais.

Em Janeiro de 20I5, a norte-americana Albermarle Corporation concluiu a aquisição da alemã Rockwood Holdings ${ }^{7}$, em uma transação em dinheiro e ações no valor de aproximadamente US\$ 6,2 bilhões. Essa combi-

4 Segundo dados do USGS, a maior mineradora australiana investiu pesadamente em 2012 para dobrar sua capacidade produtiva. O objetivo é atender a crescente demanda chinesa por espodumênio de alta qualidade para produção de compostos químicos. O crescimento do consumo mundial de concentrados foi estimado entre 7,5\% e I0\% em relação a 20 II, e verificou-se uma intensificação da pesquisa e extração em salmouras de subsuperfície (United States 2013). 5 http://www.businesswire.com/news/home/20I40528005569/en/Rockwood-Completes-Acquisition-49-Interest-Talison-Lithium\#.VPSw2_nF8RE

$6 \mathrm{http}: / /$ www.tianqigroup.cn/en/Index/aboutus.html

7 http://investors.albemarle.com/phoenix.zhtml?c=II703I\&p=irol-newsArticle\&ID=2006949 
nação reflete a criação de uma das maiores empresas de produtos químicos especiais do mundo, com posições de liderança de mercado em diversos ramos, incluindo o lítio.

Os principais desafios tanto para os países como para as empresas produtoras nos próximos anos devem incluir: projetos de expansão das suas plantas a fim de satisfazer a crescente demanda, a redução dos custos operacionais (como o resultado do aumento da produção, da produtividade das fábricas e da capacidade tecnológica), planos de investimento e desenvolvimento em plantas antigas e novas, atualização referente aos marcos regulatórios e jurisdição nos países produtores, atualização referente ao mercado de aquisições e fusões de empresas, atualização constante e quantificada sobre o estado do mercado global de veículos elétricos e observação do ambiente geopolítico mundial referente ao minério.

As empresas produtoras de lítio se resumem às quatro grandes: no Chile e na Argentina, se produzem a maior parte da oferta global de lítio em salares com SQM, Rockwood e FMC, agregadamente responsáveis por $46 \%$ da produção total de lítio. A Talison fornece $34 \%$ da produção total de lítio e um quase monopólio (65\%) da produção de lítio mineral (espodumênio) (Cormark Securities Inc. 20II).

No que tange a demanda mundial pelo lítio, o crescimento total do consumo de lítio foi em média $6,4 \%$ por ano entre 2000 e 2012 . De 2012 a 20I7, o crescimento médio anual do consumo de lítio no mundo deverá ser de aproximadamente ıı\%, impulsionado pela demanda de baterias, que cresceu em média $21 \%$ por ano entre 2000 e 2012 e espera-se que cresça $200 \%$ até 20I7, chegando a um mercado de US\$ 9 bilhões em 20I5, com potencial de ultrapassar US\$ 50 bilhões até 2020 (United States 20I2).

As empresas de tecnologia asiáticas continuam a investir no desenvolvimento de operações de lítio em outros países para garantir um fornecimento estável para suas indústrias de baterias. China, Japão e Coreia do Sul são atualmente responsáveis por $85 \%$ a $90 \%$ da produção global de bateria de lítio-ion e 60\% do consumo mundial de lítio, com 24\% da Europa e 9\% dos Estados Unidos. Esses três países asiáticos, portanto, estão gerando um crescimento elevado da demanda futura do lítio. Em 20II, a China se tornou o principal consumidor, com $33 \%$ do total mundial de consumo, com previsões de consumir quase $50 \%$ em todo o mundo em $2020^{8}$ (United States 2012).

8 "A produção de baterias de lítio na China aumentou no valor de unidades de US \$2, I bilhões em 2007 para valor de unidades de US \$ 5,4 bilhões em 20II. RIS relatarou uma previsão anual de crescimento da demanda de II\% de 20 II para 20 I7, dependendo da absorção de veículos elétricos híbridos ("HEVs") e veículos elétricos ("EVs")" (Fox-Davies 20I3). 


\section{Exportações de lítio por país de destino $-2012^{9}$}

\begin{tabular}{|c|c|c|c|c|c|c|c|c|}
\hline \multicolumn{3}{|c|}{ CARBONATO UTIO } & \multicolumn{3}{|c|}{ CLORURO UTIO } & \multicolumn{3}{|c|}{ HIDRÓXIDO LTTIO } \\
\hline Pais & Mill US\$ & \% Particip. & País & Mill USS & \% Particip. & Pais & Mill USs & \% Particip. \\
\hline Corea del Sur & 65,7 & 26,6 & China & 17,2 & 57,5 & Bélgica & 10,2 & 35,8 \\
\hline China & 53,2 & 21,5 & EE.UU. & 11,6 & 38,6 & EE.UU. & 9,7 & 34,0 \\
\hline Japón & 46,9 & 19,0 & Francia & 1,2 & 3,9 & Corea del Sur & 3,4 & 11,9 \\
\hline Bélgica & 33,5 & 13,6 & -.. & - & $\ldots$ & Singapur & 1,0 & 3,6 \\
\hline EE.UU. & 20,7 & 8,4 & -- & $\cdots$ & $\ldots$ & Argentina & 0,9 & 3,3 \\
\hline Otros & 27,0 & 10,9 & Otros & 0 & 0,0 & Otros & 3,2 & 11,4 \\
\hline TOTAL & 247,0 & 100,0 & TOTAL & 30,0 & 100,0 & TOTAL & 28,4 & 100,0 \\
\hline
\end{tabular}

Fonte: Cochilco 2013.

A China anunciou a sua intenção de se tornar um líder mundial na fabricação de híbridos e carros elétricos, tornando-se um grande player no mercado de lítio. Desta maneira, com a finalidade de assegurar o abastecimento estratégico de recursos não-renováveis e suprir seu crescente consumo interno, o governo da China criou um fundo soberano, o China Investment Corporation, em 2007, com uma carteira inicial de ativos de 200 bilhões de dólares, destinado a apoiar as iniciativas das empresas chinesas para a aquisição de jazidas não-exploradas e projetos em exploração em qualquer parte do mundo. O Estado chinês apoiou o investimento no exterior das empresas chinesas por meio da implementação de marcos regulatórios tendentes ao investimento, de subsídios diretos e indiretos, e oferecendo financiamento em condições favoráveis na forma de linhas de crédito e empréstimos com baixas taxas de juros por meio de instituições financeiras de propriedade do Estado ${ }^{\text {IO }}{ }^{\text {II }}$ (Lagos e Peters 2010, I8). Além disso, como parte de seu Plano Quinquenal para

9 Dentre as principais aplicações de produtos básicos associados ao lítio, tem-se: carbonato de lítio (elaboração de compostos para baterias Li-ion; vidros e cerâmicas; químicos e adesivos), cloreto de lítio (ar condicionados e aplicações de alumínio) e hidróxido de lítio (graxas lubrificantes e baterias Li-ion).

Io "Além da aquisição de ativos no exterior, com o mesmo propósito de assegurar o abastecimento de tais recursos, as empresas chinesas puderam estender empréstimos a investidores das indústrias mineradoras e de hidrocarbonetos, e/ou gerar contratos de abastecimento de longo prazo" (Lagos e Peters 20I0, I8). Tal estratégia geopolítica chinesa gerou preocupação com relação à possibilidade de que a China pudesse controlar o fornecimento de recursos naturais, obtendo acesso preferencial à produção e ampliando o controle sobre as indústrias extrativas no mundo.

II "O China Daily tem agora uma edição semana europeia e, em maio de 20II, publicou cinco páginas, incluindo a primeira, dedicadas ao tópico dos carros elétricos. O jornal discutiu a provável demanda futura por automóveis na China, citando o interesse do ministério da indústria e da tecnologia da informação em que haja mais de 200 milhões de veículos registrados em 2020 , bem acima dos 70 milhões em 20II. O governo anunciou seu compromisso em gastar aproximadamente US\$I5 bilhões na próxima década para impulsionar o desenvolvimento de carros elétricos" (O’Neill 2012, I38). 
20I2-I7, o governo da China vai gastar cerca de US\$ I5 bilhões para promover ainda mais o desenvolvimento de veículos elétricos por empresas chinesas, com grande parte desse investimento orientado para a pesquisa avançada de baterias de lítio (Klare 2012, I69).

Empresas automobilísticas americanas também estabeleceram metas de fabricação de carros híbridos e elétricos como cruciais para a sua prosperidade no longo prazo. Em 2009, do pacote de estímulo econômico do governo, cerca de 940 milhões de dólares foi atribuído aos produtores de baterias de lítio e seus fornecedores (Klare 20I2, I69). Como parte desse estímulo, Rockwood recebeu 28,4 milhões de dólares do governo dos Estados Unidos para a expansão da sua fábrica de carbonato de lítio existente no Nevada e para construir uma nova fábrica de hidróxido de lítio na Carolina do Norte $^{\mathrm{I} 2}$.

Em 20I2, as exportações totais de compostos de lítio nos Estados Unidos diminuíram ligeiramente em comparação com 20II. Cerca de $52 \%$ de todas as exportações dos EUA de compostos de lítio foi para o Japão, I7\% para a Alemanha, e $7 \%$ para a Bélgica. As importações de compostos de lítio para os Estados Unidos diminuíram 3\% em 20I2, em comparação com 20II. Destes, 59\% vieram do Chile e $38 \%$ a partir da Argentina (United States 20I2).

O mercado de baterias pequenas (calculadoras, computadores, câmeras, dispositivos de comunicação, etc) possui previsão de manter elevados níveis de crescimento (го\% a.a.), representando cerca de $27 \%$ do consumo mundial de lítio em 20I2, um aumento significativo com relação a anos anteriores ( $15 \%$ em 2007 e $8 \%$ em 2002). O mercado emergente de baterias grandes para bicicletas elétricas, híbridos e todos os veículos elétricos deverá crescer substancialmente (até $28 \%$ a.a.) até 2020 , ganhando maior quota de mercado. As redes de armazenamento de eletricidade são também um mercado emergente para grandes baterias de lítio, com aplicações em energia solar e reatores nucleares num futuro próximo. Os sais de lítio são usados intensivamente como fluidos em usinas de energia solar concentrada (CSP), que possui estimativa de crescimento de I.5GW em 2010 para $25 \mathrm{GW}$ em 2020 . Assim, a demanda total de lítio em baterias (todos os tipos combinados) gira em torno de 65\% do consumo total em 2025 (Fox-Davies 2013).

I2 http://www.carcelen.cl/upload/docs/Litio\%20Amcham\%20March\%2020II.pdf 


\section{Demanda por baterias de lítio}

\begin{tabular}{lrrr} 
Application / Tonnes LCE & 2011 & 2025 & CAGR 2011-2025 \\
\hline Batteries for Portable Devices & 30,416 & 111,176 & $9.7 \%$ \\
Batteries for Grid & 500 & 7,500 & $21.3 \%$ \\
Batteries for Hybrid and Electric Vehicles & 6,967 & 204,901 & $27.3 \%$ \\
Other Lithium Applications & 91,400 & 174,994 & $4.7 \%$ \\
\hline Total Lithium Demand & 129,283 & 498,571 & $10.1 \%$
\end{tabular}

Fonte: Fox-Davies 2013

Diversas empresas do ramo automobilístico estão realizando operações para suprir a sua demanda de lítio para as baterias de carros elétricos. A captação de EVs será o ponto focal de crescimento para a indústria, onde empresas como Toyota, Nissan, Ford, GM, Tata Motors e Volkswagen são apenas algumas. A Toyota, por exemplo, espera aumentar sua produção de baterias de lítio em até seis vezes, estabelecendo inclusive uma joint venture com Orocobre em um projeto de salmoura na Argentina (Fox-Davies 20I3). Da mesma forma, a Volkswagen Group, que inicia essas operações em 20I2, estabeleceu parcerias com fabricantes de baterias para iniciar a produção em massa das mesmas (United States 20I2).

Vale ressaltar que as projeções internacionais quanto à essencialidade do lítio para este novo ramo tecnológico são de difícil previsão, além de características específicas das baterias em si, cujos desafios precisam ser levados em consideração ${ }^{\mathrm{I}}$. No entanto, tem havido um grande número de programas de incentivo dos governos a nível mundial para avançar no desenvolvimento, na produção e na utilização de carros elétricos e híbridos. Apesar da incerteza de curto prazo quanto ao crescimento das baterias de lítio no segmento de veículos elétricos, acredita-se que a diminuição das emissões de carbono por parte dos governos e consumidores, assim como os investimentos significativos por uma nova tecnologia de baterias para transporte proporcionará o crescimento de uma demanda futura significativa para o lítio.

I3 "As baterias ainda precisam ser menores, pesar menos, carregar mais rapidamente e durar mais tempo com uma única carga. Também precisam provar que podem durar mais, apesar das cargas e recargas contínuas. Terão que mostrar que problemas de 'fuga térmica' - superaquecimento destrutivo - não acontecerão. [...] E o custo precisa diminuir substancialmente [...] A infraestrutura é o segundo desafio. $\mathrm{O}$ atual sistema automotivo não poderia funcionar sem a vasta rede de postos de gasolina construída ao longo de muitas décadas. Uma nova frota de carros elétricos precisará de uma rede de postos de recarga semelhante" (Yergin 20I4, 727). Entre outros fatores, poderia agregar-se a falta de padronização no tamanho das baterias para carros EV e PHEV e o custo relativamente aceitável para que seja um produto de massa, e não um produto de nicho. 
Desta forma, o lítio possivelmente se insere em uma das mudanças da matriz energética mundial, cuja dimensão ainda é incerta, haja vista que a substituição do petróleo como principal recurso estratégico ainda não está evidente e perdurará no médio prazo (Palacio 20I2, II). Num cenário otimista, o carro elétrico passaria a ocupar o centro do palco e poderia, segundo seus defensores, quebrar o domínio do petróleo sobre o transporte, gerando um impacto ambiental positivo e ajudando a reduzir a poluição através da compensação das emissões de carbono que precipitam a mudança climática, uma vez que a eletricidade que faz o carro elétrico funcionar pode ser gerada a partir de várias fontes, podendo ou não ser o petróleo uma delas. Além disso, poderia oferecer uma resposta ao aumento da frota de automóveis de um para dois bilhões e representar um caminho totalmente alternativo para o sistema energético global. "O resultado terá um impacto enorme tanto em termos de economia quanto em termos de geopolítica” (Yergin 20I4, 712).

Com o carbonato de lítio sendo um dos componentes de menor custo e de maior relevância de uma bateria de lítio-ion, a questão principal a ser abordada passa a ser a segurança do abastecimento do lítio a partir de diferentes fontes geográficas. Assim, a alta demanda do lítio no início do século XXI incentivou a prospecção e exploração de 90-I20 novas reservas, repartidos em mais de in países, como demonstra a figura abaixo.

\section{Distribuição mundial das reservas de lítio (em milhões de toneladas)}

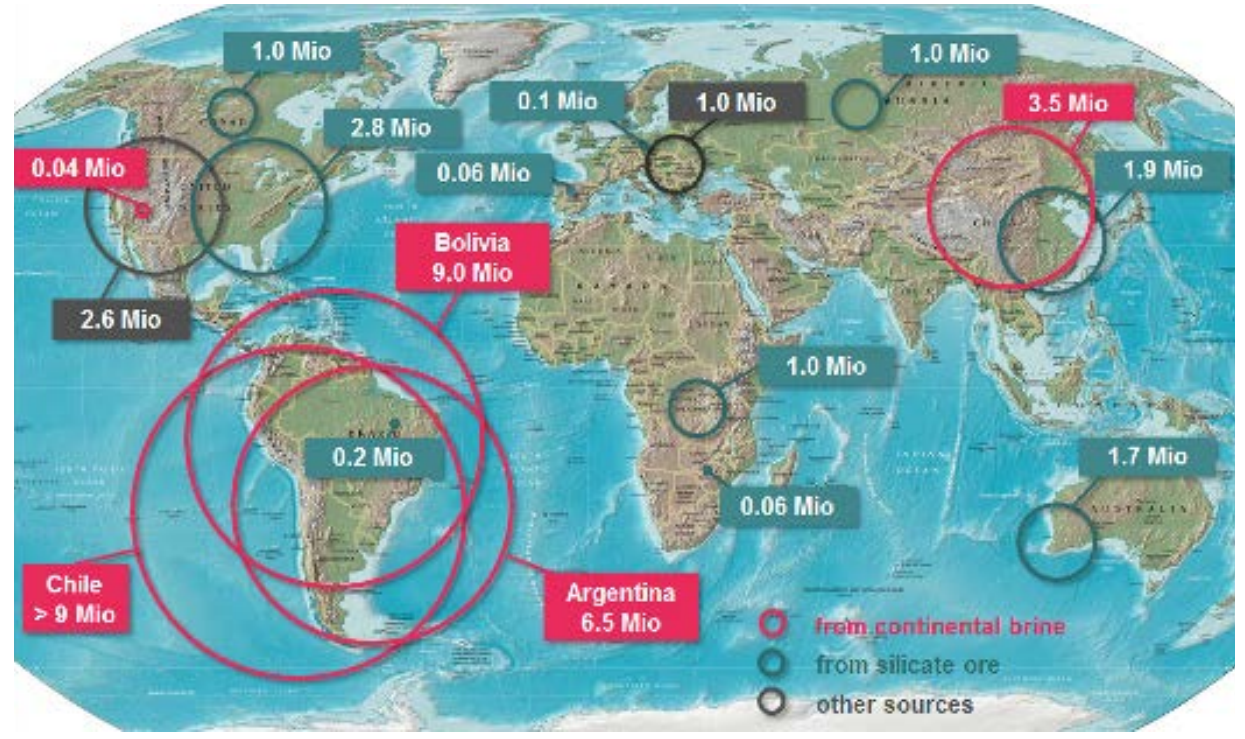

Fonte: United States 2014. 
Apesar de à primeira vista a divisão geográfica do lítio no mundo abarcar todos os continentes, sua concentração em termos absolutos é predominantemente localizada na América do Sul, mas especificamente na região andina do continente, o chamado "triângulo do lítio".

Nesta região, a sensação de isolamento determinada pela sua localização periférica na porção sudoeste do continente, por ambientes topográficos e climáticos bastante hostis (Kelly I997, 67), e pela distância dos estados vizinhos e do acesso ao mar, são características geopolíticas do triângulo. $\mathrm{O}$ isolamento não se traduz em segurança nem na falta de interesse de empresas multinacionais e países estrangeiros, que buscam fincar os pés na região. Ainda, segundo Klare $(2003,4 \mathrm{I})$, outro fator preocupante em torno ao aprovisionamento de materiais vitais, como o lítio, seria o fato da localização das mesmas estar compartida entre três países e em regiões limítrofes, onde num pequeno espaço possuem diferentes maneiras de encarar o tema, segundo três jurisdições distintas.

Triângulo do Lítio na América do Sul

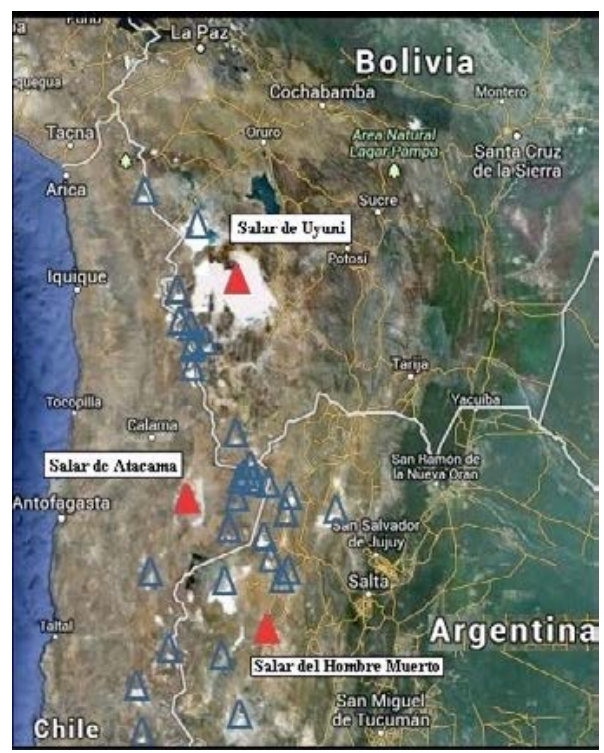

Fonte: elaboração própria, a partir de mapa do site http://triangulodellitio.com/.

\section{Distribuição das empresas no triângulo do lítio}

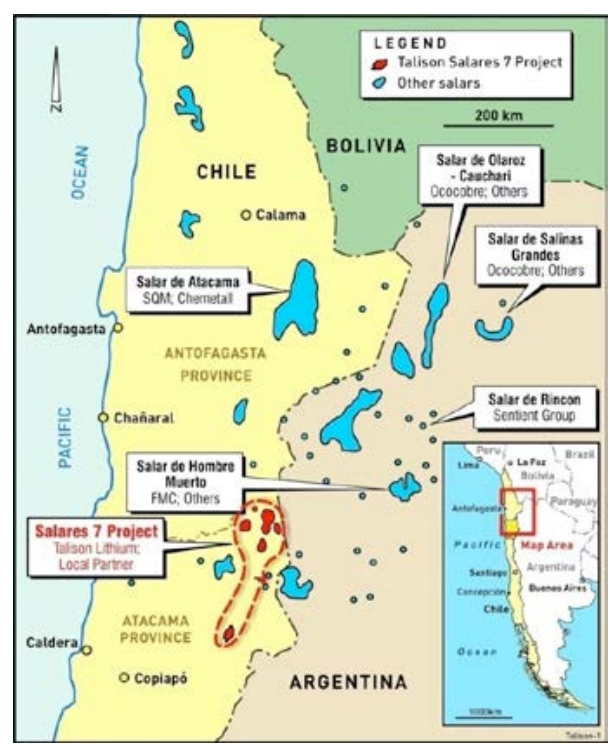

Fonte: http://www.talisonlithium.com/ sfimages/salares/salares-map.jpg.

Ainda, reitera-se que "la localización del llamado Triángulo del litio sí es una desventaja, pues la 'concentración geográfica de la producción de litio va a exacerbar las tensas relaciones geopolíticas entre América Latina y 
Estados Unidos'” (Tahil apud Palacio 20I2, 27). Ou seja, apesar das dificuldades geográficas, o triângulo consiste num dos mais promissores campos de exploração de lítio do mundo, tanto pela sua concentração num espaço relativamente pequeno, como pela sua disponibilidade e pureza que são superiores nesta região. Tal fato enseja um planejamento de longo prazo, como o promovido pelas principais partes interessadas; destas, todas as quatro grandes empresas de lítio do mundo possuem uma porção de exploração na região, como pode ser observado na imagem acima.

Assim, a região que corresponde aos salares del Hombre Muerto, de Atacama e Uyuni, o chamado triángulo del lítio, ou ainda a Saudi Arabia of lithium , é considerada altamente estratégica para a nova etapa de acumulação capitalista e para a reprodução de seu modo de produção. Este novo ABC sul-americano, portanto, se insere numa nova pressão competitiva mundial que tende a se acentuar ainda mais com o aumento da demanda mundial pelo recurso.

Em termos geopolíticos, tudo indica que a América do Sul em geral foi incorporada na pressão competitiva mundial em que algumas regiões, como o próprio triângulo do lítio, "devem se transformar em 'zonas de fratura' internacional, e aí podem surgir conflitos e rebeliões que envolvam as grandes potências e as empresas que competem pelo controle da região" (Fiori 20I4, I6I). Ainda, o estudo geopolítico do oro gris permite analisar a construção de distintas estratégias nacionais, políticas públicas, instituições e regulações dos três países com reservas na América do Sul - Argentina, Bolívia e Chile -, suas disputas internas e no âmbito internacional e as conexões entre atores internos e externos, conectando as perspectivas nacional, regional e mundial.

\section{Por uma Geoestratégia do $A B C$ do lítio}

Deve-se compreender, analisar e utilizar a geopolítica como "um conhecimento estratégico e normativo que avalia e redesenha a própria geografia a partir de algum projeto de poder específico, defensivo ou expansivo" (Fiori 20I4, I4I). Este projeto de poder deve buscar alavancar o desenvolvimento regional na América do Sul ancorado numa simbiose política (progressista e autônoma), econômica (produtiva, comercial e tecnológica), social (redução das assimetrias e desigualdades regionais) e geopolítica (expansão política e econômica internacional).

Assim, constata-se que a viabilidade de uma geoestratégia do $\mathrm{ABC}$ do lítio consiste num dos pilares constituintes de um projeto de integração regional focado nos recursos naturais estratégicos. Entretanto, há que se atentar 
que, na busca dessa geoestratégia, estes Estados devem "desrespeitar" sistematicamente as regras, instituições e coerções dos mercados e do conjunto dos grandes centros de poder contrários à sua emancipação político-econômica, indo na contramão da "ordem institucional estabelecida e os grandes acordos geopolíticos em que se sustenta" (Fiori 20I4, 276). Ao priorizar os interesses geoestratégicos conjuntos que, apesar de unilateralmente serem, a princípio, contraditórios - como é o caso da concepção geoestratégica da Argentina voltada para o Atlântico, da Bolívia sem acesso ao mar e do Chile voltado ao Pacífico, por exemplo - esses Estados podem se transformar num elemento coesivo de mudança de suas posições relativas dentro desse sistema.

Atualmente, constata-se que as estratégicas referentes ao lítio nos três países são distintas. Na Argentina, as empresas e o Estado impulsionam a industrialização com o capital privado, recebendo questionamentos dos moradores diretamente afetados; na Bolívia, a estratégia se baseia basicamente na forma de financiamento do projeto estatal, propondo-se seu controle por parte do Estado; e no Chile, as decisões de permissão ou não da participação privada na exploração do lítio se limita ao âmbito do Estado - mas que não possui seu controle - numa oposição entre o governo e os partidos políticos de oposição (Palacio 20I2, I7).

Constata-se que na Argentina e no Chile há um total predomínio do capital estrangeiro, situação similar à extração de outros metais estratégicos. Esses capitais que, nos últimos I5 anos, vêm realizando investimentos cada vez maiores e se posicionando em zonas específicas, atualmente possuem praticamente a totalidade das reservas de lítio comprovadas. Além disso, grande parte dessas companhias extrativas possuem vínculos diretos com empresas automobilísticas ou altamente demandantes de lítio.

Caso distinto é encontrado na Bolívia, onde se implementa uma política de alianças corporativas com organizações populares e outros sujeitos sociais, no qual o governo se situa no debate em uma posição à esquerda dos seus críticos neoliberais, ensejando uma legitimidade ao seu discurso frente aos projetos nacionais. Entretanto, as nações vizinhas não compartilham com o pensamento de independência econômica que priorize as nações detentoras dos recursos. Acabam, assim, minando as oportunidades de desenvolvimento sustentável da Bolívia na região, ao oferecer grandes quantidades de lítio às mineradoras estrangeiras a um custo bem mais baixo do que o boliviano, uma vez que a base do modelo de exploração do mineral que vigora na Argentina e no Chile abarca os velhos padrões capitalistas de exploração dos recursos naturais, "no qual os lucros se acumulam nas mãos dos detentores do capital, enquanto a região explorada é degradada, não se desenvolve e seus trabalhadores vivem na miséria absoluta" (Wright 2010). 
Como pode ser observada no caso específico da Bolívia, a reafirmação do lítio para a "soberania energética" e como "recurso estratégico" - neste caso também para o Chile - se manifesta em diferentes dimensões: controle da exploração propriamente dita dos recursos, volumes extraídos e eventualmente exportados, dos investimentos em exploração e em infraestrutura de transportes; questão da partilha dos lucros obtidos com a atividade; utilização dos recursos obtidos em projetos de desenvolvimento econômico e social, além da busca de estimular novas cadeias produtivas a partir de uma industrialização endógena do lítio.

Observa-se que a geoestratégia global do lítio se encontra em plena fase de acumulação e concentração de capital, ratificado pelas aquisições, fusões e joint ventures de diversas empresas do ramo. Tal fato não exclui a América do Sul deste processo, onde essas empresas possuem operações e controlam grande parte das reservas e produção de lítio da região, de acordo com os planejamentos estratégicos de suas matrizes estrangeiras. Concomitantemente, a constatação de que, num futuro próximo e com produção plena, Argentina, Bolívia e Chile irão administrar o mercado do lítio, enseja uma discussão acerca de um planejamento estratégico baseado neste recurso.

O desenvolvimento econômico regional não pode ser compreendido e explicado isoladamente ou a partir de fatores únicos e exclusivamente endógenos. Como afirma Fiori (20I4, 37), "o desenvolvimento econômico obedeceu a estratégias e seguiu caminhos que foram desenhados em resposta a grandes desafios sistêmicos, de natureza geopolítica". Alinhado as coalizões de interesse, de classe ou de governo, há de se formar um bloco de poder que responda a esses desafios externos através de estratégias e de políticas de fortalecimento econômico de longo prazo, que reivindique mudanças "nas regras de gestão do sistema mundial e na sua distribuição hierárquica e desigual do poder e da riqueza" (Fiori 20I4, 35).

Para Medeiros (2013, I57-I58), é necessária uma estratégia nacional e, a partir do presente trabalho, concomitantemente regional - denominada de "nacionalismo dos recursos naturais", que abrange uma disputa política que envolve o poder sobre os recursos naturais e a segurança energética de produtores e consumidores. Medeiros afirma que o controle e coordenação dos recursos naturais deve ser realizado pelo Estado, numa estratégia estatal de desenvolvimento e de reconstrução via nacionalização dos recursos naturais que engendre uma autonomia política e fiscal para os Estados em relação aos interesses privados e internacionais, envolvendo complexos desafios geopolíticos. Assim, esta estratégia se basearia na "exploração das possibilidades industriais ao longo da cadeia de valor dos recursos naturais" (Medeiros 2013, I64), ainda que com grandes desafios, como a "grande dependência de seus 
preços instáveis, sua estrutural vulnerabilidade financeira e os constantes desafios criados pelo progresso técnico" (Medeiros 2013, I65).

Dentre os demais desafios, pode-se citar a "fraqueza das conexões entre acumulação de capital, progresso técnico, mudança estrutural e evolução institucional" (Medeiros 20I3, I50). Ou seja, um desenvolvimento baseado nos recursos naturais pode gerar uma particular estrutura social de acumulação que pode bloquear a mudança estrutural a partir do momento em que o crescimento econômico pode ser alcançado sem que novas estruturas tecnológicas sejam realizadas, não modificando os problemas macroeconômicos que dominam a agenda da política econômica, as instituições e o Estado.

Bruckmann defende a necessidade de pensar os ciclos da inovação científico-tecnológica e os ciclos econômicos com relação ao uso, à transformação, à apropriação e ao consumo dos recursos naturais, permitindo avaliar as tendências de consumo de minerais na economia mundial. Assim, segundo a autora, trata-se atualmente de um embate entre dois modelos de desenvolvimento baseados nos recursos naturais estratégicos:

um baseado na planificação e no uso sustentável dos recursos naturais dirigidos a atender às necessidades da maioria dos atores sociais; e o outro baseado na exploração e na expropriação violenta e militarizada destes recursos e das forças sociais e dos povos que os detêm (Bruckmann 20II, I98).

Dessa forma, a busca, planificação e proteção dos recursos naturais estratégicos passam a constituir uma das funções primordiais de segurança a cargo do Estado. Alguns estudiosos afirmam que os limites de exportação buscam encorajar firmas estrangeiras a instalar suas operações de manufaturas de alta tecnologia, que necessitam das terras raras, em território chinês (Klare 20I2, I58-I59), instaurando assim um ciclo virtuoso para regiões mais pobres do país, onde se localizam as maiores reservas. Ou seja, caso tal controle sobre os recursos e limitação de exportações fosse adotado como política conjunta dos três países, as consequências positivas poderiam se assemelhar as constatadas com a iniciativa chinesa.

Como destaca Kelly (I997, I59), "major domestic groups have come to recognize that without South American integration, local economies could be exposed to a global 'marginalization'". Em outras palavras, a orientação cooperativa e unificadora na forma de integração, a realização de blocos regionais autônomos e soberanos se apresentam como um caminho prático para a nova realidade da região nas relações internacionais. De fato, a cooperação interna, mais do que o conflito, desponta com proeminência na geopolítica 
sul-americana contemporânea.

\section{Conclusão}

No presente trabalhou buscou-se a utilização da geopolítica como método de estudo da economia política internacional dos países da América do Sul, tendo como eixo os recursos naturais estratégicos, mais especificamente o lítio.

Sabe-se que mesmo que nos enveredemos para estudos geopolíticos periféricos sul-americanos, os grandes centros de poder mundiais também realizam prognósticos sistemáticos acerca da geopolítica na América do Sul e no mundo e, indubitavelmente, choques geopolíticos estão presentes na arena internacional. A acumulação de poder e riqueza consiste no cerne da questão e, assim, é fundamental compreender as configurações geopolíticas da região.

Em suma, o conjunto de cinco propostas delineadas abaixo abrange diretrizes para uma geopolítica dos recursos naturais estratégicos na região. Desta forma, no caso específico do lítio, essas iniciativas deveriam ser debatidas em conjunto pelos três países, conformando assim uma geopolítica regional do lítio:

- Planificação regional de segurança e proteção dos recursos: a segurança estratégica dos recursos naturais deve fazer parte de um projeto regional, tendo os organismos técnicos do Estado, principalmente as forças armadas, a obrigação de defender essas novas fontes naturais existentes no solo nativo. Tal fato será ainda mais importante quando se agravarem a falta de energia, água, matérias-primas e alimentos no cenário mundial. Desse cenário internacional hipotético, se impõe como um objetivo vital a intensificação das forças armadas sul-americanas, nos marcos do Conselho de Defesa Sul-Americano da Unasul, para que se possa ter uma capacidade dissuasiva-estratégica;

- Política de Industrialização endógena: a geopolítica do lítio na região enseja a necessidade de se elaborar uma política regional de industrialização do lítio, que movimente a produção de baterias recarregáveis de dispositivos eletrônicos portáteis e carros elétricos do Sudeste asiático para a América do Sul. Esta política regional deverá ser planificada continentalmente, determinando quais setores produtivos do sistema sul-americano poderiam adquirir competitividade internacional, transformando-os em setores de interesse coletivo de todos os países que conformem a área de integração, apropriando-se da pesquisa científica e tecnológica em relação ao mineral e 
desenvolvendo todo o seu ciclo, desde sua exploração mineira ao desenvolvimento industrial local, logrando uma indústria com alto valor agregado;

- Participação no estabelecimento dos preços internacionais: a partir do momento que a região possui grande concentração das reservas mundiais de recursos estratégicos, ela possui ampla capacidade de negociação e de formação internacional de preço. Uma vez que Argentina, Bolívia e Chile controlam a quase totalidade de reservas do lítio, as três nações poderiam configurar uma organização similar a dos países produtores de petróleo, com a capacidade de tomar medidas que incidam, futuramente, na regulação dos preços do metal;

- Efetiva governança pública nacional dos recursos naturais: tal prerrogativa envolve aspectos regulatórios, fiscais, de gestão macroeconômica, planejamento estratégico, formulação e implementação de políticas públicas. Assim, deve-se institucionalizar mecanismos anticíclicos frente à volatilidade inerente aos preços internacionais dos produtos primários exportados pela região, aumentando a progressividade na participação do Estado na renda da exploração - sobretudo nos ciclos de alta dos preços - a fim de que se possam desenvolver mecanismos que assegurem o investimento público eficiente da renda derivada da exploração de recursos naturais em educação, saúde, infraestrutura, inovação e desenvolvimento tecnológico, além da sua distribuição equitativa entre grupos sociais e níveis de governo;

- Medição do impacto ambiental e social: conseguir administrar e medir de maneira eficaz os conflitos socioambientais que inevitavelmente surgem durante o desenvolvimento dos setores de recursos naturais, realizando cálculos de taxas de compensação, estratégias de recuperação ambiental e diminuição de externalidades negativas.

A gestão dos recursos naturais é um processo dinâmico e requer acompanhamento cuidadoso. A informação e conhecimento são fontes fundamentais para a política e tomada de decisão, de modo que é indispensável a criação de instrumentos para avançar nessa direção. É necessário um trabalho de pesquisa permanente e sistemático para aprofundar o estudo e conhecimento das várias dimensões que envolvem o uso de recursos naturais como base para o desenvolvimento integral da região.

\section{REFERÊNCIAS}

Baylis, Robert. 20I2. "Vehicle electrification and other lithium end-uses: How big and how quickly?". Proceedings of 4th Lithium Supply \& Markets Conference, Buenos Aires, Argentina. 
Brasil. 20I3. Departamento Nacional De Produção Mineral. Sumário Mineral 2013.

Bruckmann, Monica. 20II. "Recursos naturais e a geopolítica da integração sul-americana”. In Governança Global e a integração da América do Sul, 197-246. Brasília: IPEA.

Bruckmann, Monica. 20II. “Ou inventamos ou erramos: a nova conjuntura latino-americana e o pensamento crítico". Doutorado, Universidade Federal Fluminense.

Cochilco (Comisión Chilena del Cobre). 2013. Monitoreo de los minerales industriales de Chile: Análisis de los recursos salinos 2013. Chile.

Cormark Securities Inc. 20II. Lithium Producers and Developers.

Fiori, José Luís. 20I4. História, estratégia e desenvolvimento: para uma geopolítica do capitalismo. São Paulo: Boitempo.

Fox-Davies. 2013. The Lithium Market. http://doc.xueqiu. com/1497add847II93fc2e583642.pdf.

Kelly, Philip. I997. Checkerboards and Shatterbelts: The geopolitics of South America. Austin: University of Texas Press.

Klare, Michael. 2003. Guerras por los recursos: El futuro escenario del conflicto global. Barcelona: Ediciones Urano.

2013. The race for what's left: The global scramble for the world's last resources. New York: Picador.

Lagos, Gustavo. 20II. "Análisis histórico industria del litio". In El Debate Sobre el Litio. Santiago: Universidad Católica de Chile. https://intrawww. ing.puc.cl/siding/datos/departamentos/files/imm/orGustavoLagos_ AnalisishistoricoindustriadellitioI7_II_II.pdf.

Lagos, Gustavo e David Peters. 2010. "O sector mineiro da América do Sul". Plataforma Democrática. October 23. http://www.plataformademocratica.org/Publicacoes/18047.pdf.

Libertad y Desarrollo. 2012. "Licitación del Litio: ¿Mineral 'Estratégico'?”. Temas públicos (1067).

Medeiros, Carlos. 2013. "Recursos naturais, nacionalismo e estratégias de desenvolvimento". Oikos I2 (2): I43-167.

O’Neill, Jim. 20I2. O mapa do crescimento: oportunidades econômicas nos BRICs e além deles. São Paulo: Globo.

Palacio, Luis Emilio Riva. 20I2. "Del Triángulo del litio y el desarrollo sustentable.: Una crítica del debate sobre la explotación de litio en Sudamérica en el marco del desarrollo capitalista". Observatorio Latinoamericano 
de Geopolitica. November 27. http://www.geopolitica.ws/document/ del-triangulo-del-litio-y-el-desarrollo-sustentabl.

United States. 20I2. U.S.Geological Survey. Minerals Yearbook. Lithium [Advance release]. 2013. U.S. Geological Survey. Mineral Commodity Summaries 2013. 20I4. U.S.Geological Survey. Mineral Commodity Summaries 2014.

Viana, André, Pedro Silva Barros, and André Bojikian Calixtre. 2orı. Governança Global e Integração da América do Sul. Brasília: IPEA.

Wright, Lawrence. 2010. "Sonhos de lítio". Piauí 45.

Yergin, Daniel. 20I4. A busca: Energia, segurança e a reconstrução do mundo moderno. Rio de Janeiro: Intrínseca.

\section{RESUMO}

O presente artigo parte da hipótese do lítio como um dos recursos naturais mais estratégicos, cujas reservas mundiais, quantitativamente e qualitativamente, se concentram na região sul-americana. Desta maneira, o presente artigo apresenta uma análise geopolítica do lítio com a finalidade de definir possibilidades geoestratégicas para a América do Sul.

\section{PALAVRAS-CHAVE}

Geopolítica; Lítio; América do Sul.

Recebido em 3 de agosto de 2016. Aprovado em 25 de novembro de 2016. 